ISSN: 2446-6549

|Seção: Relato de Experiência|

DOI: http://dx.doi.org/10.18764/2446-6549.e202031

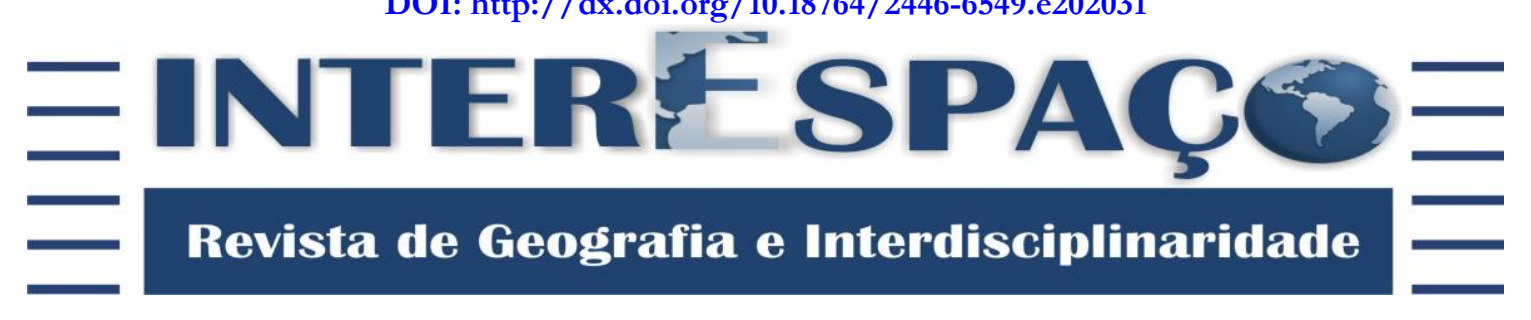

\title{
A CAMINHO DO LUGAR E DE PASSAGEM: tão perto e tão longe de Vila Mariana ${ }^{1}$
}

\section{ON ITS WAY AND PASSING BY IT: so close and so far from Vila Mariana}

EN SU CAMINO Y DE PASAJE: tan cerca y tan lejos de Vila Mariana

\author{
Cilene Gomes \\ Doutora em Geografia Humana pela Universidade de São Paulo - USP. Docente e Pesquisadora do \\ Programa de Pós-Graduação em Planejamento Urbano e Regional da Universidade do Vale do \\ Paraíba - UNIVAP/SP. \\ cilenegs@univap.br / http://orcid.org/0000-0001-5217-9426
}

Recebido para avaliação em 18/12/2019; Aprovado para publicação em 08/12/2020.

\section{RESUMO}

Em direção ao casarão branco, sede do Centro de Estudos da Metrópole (CEM), em São Paulo, curiosa convergência de momentos já havia se instalado no espírito criando expectativas ao novo. O curso e o experimento etnográfico faziam confluir, em simultâneo, três intenções, delineadas na vontade, em tempos diferentes: conhecer melhor alguns bairros paulistanos; visitar a Galeria Jacques Ardies, de arte naif, e a Sociedade Brasileira de Psicologia Analítica, ambas localizadas a pequena distância do CEM. A perspectiva da etnografia urbana vinha desconstruir o modo de olhar a cidade e nela permanecer, e o modo de conhecê-la. Ao estabelecer a observação, leitura e significação de espaços urbanos, a partir da imersão possível do pesquisador no instante presente do lugar social que o constitui, e com base nos achados da experimentação e múltiplas conexões significativas que se desenharam durante o relato do experimento e a reflexão, o novo princípio metodológico vinha engendrar a possibilidade de outras experiências espaço-temporais dos lugares de vida social e de acesso a novos aportes para os estudos urbanos e regionais. Com o relato, objetiva-se compartilhar a nova experiência de olhar para o cotidiano da cidade.

Palavras-chave: Observação Etnográfica; Urbanidade; Bairros; São Paulo.

\section{ABSTRACT}

Towards the White House, headquarters of the Center for Metropolitan Studies (CEM), in São Paulo, curious convergence of moments had already settled in the spirit creating expectations for the new. The course and the ethnographic experiment simultaneously brought three intentions, outlined at will, at different times: to know better some neighborhoods in São Paulo; visit the Jacques Ardies Gallery of Naive Art and the Brazilian Society of Analytical Psychology, both within walking distance of CEM. Moreover, the perspective of urban ethnography came to deconstruct the way of looking at and staying in the city, and the way of knowing it. By establishing the observation, reading and meaning of urban spaces, from the possible immersion of the researcher in the present instant of the social place that constitutes it, and based on the findings of experimentation and multiple significant connections that were drawn during the report of the experiment and the on reflection, the new methodological principle created the possibility of other

\footnotetext{
${ }^{1}$ Este relato resulta de um experimento de observação etnográfica entregue como exigência para avaliação final, ao curso Etnografias Urbanas: Epistemologia, Experiência, Exercício, de responsabilidade de Gabriel Feltran, Deborah Fromm e André de Pieri. Série Metodológicas, CEM, de 17 a 19 de outubro de 2016.
} 
|Cilene Gomes |

spatiotemporal experiences of social places of life and of access to new contributions to urban and regional studies. The objective is to share the new experience of looking at the daily life of the city.

Keywords: Ethnographic Observation; Urbanity; Neighborhoods; São Paulo.

\section{RESUMEN}

Hacia la Casa Blanca, sede del Centro de Estudios Metropolitanos (CEM), en São Paulo, la curiosa convergencia de momentos ya se había establecido en el espíritu creando expectativas para lo nuevo. El curso y el experimento etnográfico reunieron simultáneamente tres intenciones, esbozadas a voluntad, en diferentes momentos: conocer mejor algunos barrios de São Paulo; Visite la Galería de Arte Naive Jacques Ardies y la Sociedad Brasileña de Psicología Analítica, ambas muy cerca del CEM. Además, la perspectiva de la etnografía urbana llegó a deconstruir la forma de mirar y permanecer en la ciudad, y la forma de conocerla. Al establecer la observación, lectura y significado de los espacios urbanos, a partir de la posible inmersión del investigador en el instante presente del lugar social que lo constituye, y en base a los resultados de la experimentación y las múltiples conexiones significativas que se extrajeron durante el informe del experimento y el Reflexión, el nuevo principio metodológico creó la posibilidad de otras experiencias espaciotemporales de los lugares de vida social y el acceso a nuevas contribuciones a los estudios urbanos y regionales. Con el informe, el objetivo es compartir la nueva experiencia de mirar el día a día de la ciudad.

Palabras clave: Observación Etnográfica; Urbanidad; Barrios; São Paulo.

\section{INTRODUÇÃO - Estar presente e observar para refletir}

A ideia era caminhar pelo bairro de Vila Mariana e proximidades, não à deriva, mas com o objetivo de refletir sobre a urbanidade contemporânea ao observar as interações humanas, os encontros, a paisagem. Ao sair da sala de aula, no primeiro dia, o olhar já era outro, algo assim como um ajuste instantâneo da lente fotográfica para dar nitidez ao foco. Uma atenção alerta havia sido imediatamente acionada para avivar a presença no lugar da observação. Ao mesmo tempo em que procurava captar o mais possível o que tinha diante dos olhos, sentia-me integrada ao local, com uma clara pré-disposição ao diálogo. No passo espontâneo de um alguém qualquer no fluxo dos acontecimentos, o experimento iniciava.

Com o objetivo de compartilhar essa nova experiência do olhar etnográfico, o limiar do reconhecimento do Outro e do Eu no espaço daquela vivência do cotidiano da grande cidade tornara-se pleno de expectativas.

\section{DE PASSAGEM POR VILA MARIANA, O COMUM E O DESTOANTE}

Logo pensei, era preciso aceitar o fato de perceber as cenas comuns do cotidiano. Não seria a inteira disposição à observação-participante que criaria em instantes os acontecimentos inusitados que o pesquisador esperava encontrar. Era o aqui e agora. 
|Cilene Gomes |

Pessoas magnetizadas por seus celulares saltavam aos olhos, encantoadas na Estação Santa Cruz do Metrô ou andando pelas calçadas, digitando, com fones de ouvido, conversando, cantando sozinhas, conectadas ao seu mundo. Eu nem podia esboçar espanto, pois não escapava ao comportamento.

Resolvi entrar na farmácia para comprar band-aid. Comecei a prestar atenção naquele espaço, nas pessoas paradas nas filas, para pedir algum produto ou pagar, e nas que percorriam as prateleiras. Senti necessidade de informar a um vendedor que teria que sentar num banquinho disponível perto do balcão para colocar o band-aid no meu calcanhar. Já na fila para pagar, outra cena comum entre mãe e filho não me surpreende, quando a criança chega até a mãe, atrás de mim na fila, e acometido pela vontade de consumo, pergunta se poderiam levar tal pasta de dente cremosa.

Sai da farmácia e segui meu caminho observando o movimento intenso do final de tarde. Muita gente circulando, no cruzamento ou ponto de ônibus, ou papeando e tomando algo em mesas na calçada. Ao dobrar a Rua Doutor Altino Arantes, outra cena frequente nos finais de tarde do bairro novamente se apresentou: gente de chinelo passeando com cachorro.

No segundo dia da caminhada, outras cenas do dia a dia acresciam-se à minha observação: pedaços de conversas soltas ao vento, em mesas de bar ou no jornaleiro da esquina, menino pequeno com camiseta do super-homem e mochila, jovens meninas usando shorts e adereços despojados, em frente ao núcleo de design da Belas Artes, papelaria universitária, jovens meninos carregando seus notebooks como se fossem cadernos.

No shopping popular da Rua Pelotas, afora o grande vazio dos corredores e das lojasbox, uma ou outra mulher carregava sacola de compras. Seguindo pela Rua Áurea, em meio à sombra do início de final de tarde, avistei duas mulheres idosas: uma no portão do lado de dentro da casa, apreciando o movimento da rua, junto a um cachorro preto que andava pelo jardim pra lá e pra cá, e a outra caminhando, amparada por uma mulher mais moça.

Mas para a minha surpresa, algo destoava dos lugares comuns de Vila Mariana: a pirâmide azul da Mens Sana na Rua Rodrigues Alves e o comércio de pianos de cauda na Rua do Instituto Biológico. Em direção ao bairro do Paraiso, a própria avenida 23 de Maio, vista da ponte que liga à Rua Tutóia, na condição de pedestre, me impactou com sua identidade escancarada de poderoso corte topológico da estrutura dos bairros das imediações, assim como a Rodovia Dutra que separa ao meio cidades do Vale do Paraíba.

$\mathrm{Na}$ iminência da hora de conhecer o centro de estudos de psicologia analítica, diante de um portão duplo e cerrado, que ocultava a casa grande (de estilo mais recente do que os casarões da Vila Mariana), e tornava recôndita a atmosfera sóbria do centro de 
|Cilene Gomes |

estudos, a mediação pela campainha e interfone me constrangeu um pouco, mas ao acionála, ninguém falou nada e o portão logo se abriu. O centro era todo ele dissonante da vida urbana nas ruas. As grandes salas de aula vazias, com cadeiras dispostas em formas abertas de organização, os murais cheios de fotografias de pessoas frequentadoras e os dois grandes quadros com as imagens de Jung e Freud em locais contrapostos no andar superior da casa, a revista Conexões, todo o conjunto da experiência no interior da casa de estudos parecera me deslocar do espaço de observação e do plano consciente do experimento levando-me, por minutos, a imersões no insondável universo do que não é visível.

Seguindo de volta à Vila Mariana, entrei no bazar da Igreja Santíssimo Sacramento, de portas abertas ao nível da rua, e perguntei à senhora atendente se a ambulante que estava com sua mesa de bijuterias em frente ao bazar (quando por lá passei na ida) tinha a ver com o bazar. Calei ao saber que a moça comprava no bazar para revender na calçada, e disse à senhora estar apenas curiosa quando ela me perguntou se eu era da prefeitura.

A estratégia de sobrevivência da moça parecia não condizer com os bairros bem providos dos arredores. E muito menos concordante com o conforto daquelas paragens da grande metrópole pareceu-me a condição indigna de dois homens sentados no chão, um encostado no poste de um cruzamento de rua movimentada, e outro, prostrado em frente a um bar. O todo metropolitano criador de riquezas, junto a inúmeras contradições e sinais de ausência de política pública, fazia-se representar naquele ponto do espaço.

Outras cenas destoaram no percurso, mas também com seu tom de algo comum: alguns sorriem ao cruzar com a gente, outros se escondem dentro de si mesmos ou são indiferentes ao nosso olhar. Carrinho de pipoca vendia batata-frita e a placa de um metro de altura apoiada no chão anunciava que "família vende tudo". Jovem vestindo uniforme de colégio, saindo de edifício poderoso, na segurança e arquitetura, ao ser por mim interrogado, respondeu: - Isso é um problema, mas não consigo lembrar o nome da rua em que moro.

A luminosidade branca do céu em forte contraste com os ramos escuros das árvores altas da Rua Morgado de Mateus anunciava a hora de não tardar a ir para a galeria de arte naif, outra ambiência inusitada nos interiores da paisagem de Vila Mariana. Eis um bom passo aos achados e encontros significativos da observação-participante.

\section{ACHADOS E ENCONTROS}

Descendo pela calçada do colégio Nossa Senhora do Rosário, percebi a fila organizada de carros que subiam bem próximos à guia até chegarem em frente a porta da 
|Cilene Gomes |

escola, onde seus motoristas anunciariam o nome da criança (que vinham buscar) a uns rapazes uniformizados, usando coletes com faixas luminosas, que transitavam pela calçada e transmitiam por rádio para dentro da escola o nome da criança para que esta fosse chamada por alto-falante e viesse para a saída e fosse entregue aos responsáveis pelo mesmo rapaz do rádio. Quem vinha buscar a criança nem descia do carro. Um achado interessante para pensar no espaço condicionante do tempo e da prática social.

Continuei descendo pela calçada e avistei mais adiante um carrinho de pipoca próximo de outra porta do colégio de onde sairiam, mais tarde, as crianças e jovens que permaneciam na escola para praticar esportes. Ao me aproximar do carrinho, percebi que a senhora estava girando a panela e aquela fumaça de cheiro me deu vontade de comer pipoca. Neste momento lembrei-me do experimento e fiquei contente, pois havia criado uma ocasião para interagir com a senhora pipoqueira, morena e magra, que usava uma redinha preta na cabeça e avental branco com o nome bordado no bolso do lado esquerdo.

Pedi uma pipoca salgada e enquanto esperava ficar pronta comecei a observar o carrinho: era prateado na parte de baixo e na superior era de vidro e dividido em três partes, sendo um compartimento grande para pipoca salgada, e dois outros menores, um para a pipoca doce (bem vermelha), e o outro, onde havia saquinhos preparados com amendoim açucarado, o praliné, que aprendi um dia a fazer com minha amiga gaúcha. Achei curioso que dentro do espaço de vidro, onde ficava a pipoca salgada, havia uma iluminação, e nos braços do carrinho, um saquinho de supermercado pendurado para o lixo.

Era hora do lusco-fusco, o anoitecer. Quando ela me deu a pipoca, notei que não vinha naquele saquinho branco tradicional. Era uma embalagem de papelão grosso, com um marketing impresso, meio sinistro, propaganda de filme ou super-herói, nem me interessei.

Pensando em dar um tempo para prolongar a observação da cena, disse a ela que ficaria um pouco por ali, pois eu poderia querer mais sal na pipoca. Fiquei ao lado do carrinho e percebi que, na parte de trás, havia outro suporte para o saco de milho (como um saco de 5 quilos de arroz), o óleo e o sal. Na lateral do carrinho, vi o lugar da panela de pipoca.

Logo que ela me serviu, disse a ela que eu tinha estudado naquele colégio desde criança até uns 14, 15 anos, não lembrava. Ela me disse que antes o colégio era só de meninas, e eu disse a ela que quando eu estudava lá, de fato era só de meninas, mas que ainda no meu tempo já havia mudado para misto. Contei que no tempo em que o colégio era só de meninas, eu tomava ônibus para ir pra casa, e que ficava um monte de meninas no ponto do ônibus, e quando o ônibus vinha, ele vinha cheio de meninos que estudavam 
|Cilene Gomes |

no colégio Arquidiocesano (que era só de meninos e que depois virou misto também) e que juntava tudo e ficava aquela algazarra no ônibus. Ela achou engraçado.

Dali eu observava o movimento da saída do colégio. Perguntei a ela se ela vendia bastante e até que horas ficava por ali. Ela disse que de manhã não vinha, porque não vendia, e que vinha só à tarde e ficava até 21 horas, quando as crianças e jovens saiam do colégio após os esportes. Disse que fazia a pipoca conforme a venda, para sempre vender quentinha.

Aproximaram-se dois meninos japoneses, provavelmente irmãos. Pediram duas pipocas de 5 reais com bacon. A senhora disse que não tinha com bacon e eles aceitaram a pipoca simples. Vi que o saquinho de 5 reais era mais estreito na base e mais alto do que o meu, de 4 reais, e era mais bonito também, com uns desenhos geométricos em vermelho e azul. Fiquei meio arrependida de não ter pedido a pipoca de 5 reais, e mais ainda quando ela fez questão de me dar um "chorinho". Disse a ela que deveria inteirar com 1 real pelo chorinho e ela disse que não precisava. Pensei que voltaria outro dia, em troca da gentileza.

Depois se aproximou um homem que disse ter vindo acertar os 5 reais que devia de outro dia. A pipoqueira disse que uma das filhas dele tinha acabado de pegar outra pipoca, com o guarda da porta que fazia a mediação entre a senhora pipoqueira e a criança dentro do colégio. O pai perguntou qual das filhas tinha pedido a pipoca, e a senhora não sabia ao certo o nome da menina. Ele disse que tudo bem, mas a senhora disse que ia perguntar para o guarda, pois era importante dizer certinho quem havia pegado a pipoca. O guarda informou que teria sido a filha Isabela. O pai então pagou e foi embora.

Em seguida, uma mulher que dirigia um dos carros da fila (que iam passando em frente o carrinho de pipoca), disse pela janela do carro que queria acertar os 5 reais de outro dia. A vendedora perguntou: - E vai querer outra pipoca hoje, Mãe? A moça do carro disse que queria uma salgada com um pouco de pipoca doce por cima. Daí a senhora foi preparar a pipoca doce, embora ainda tivesse bastante lá no carrinho. Vi então que ela despejou o açúcar na panela, um pó vermelho, óleo e água. Perguntei sobre o pó, que me pareceu da cor do açaí, e ela disse que era um corante. Não a vi terminar de fazer, resolvi ir embora.

No dia seguinte, após duas horas de observação, resolvi entrar na padaria Via Áurea dos Pães e tomar um café. Pelo horário, estava bem situada para retornar à sala de aula. Notei que tinha uma televisão, gente assistindo, e um movimento habitual de padaria no final de tarde. Sentei e pedi um café. Ao meu lado tinha uma moça jovem, com cabelos pretos e compridos, usando um batom cor de rosa forte, com mochila nas pernas, olhando o cardápio sobre o balcão e conversando com a jovem senhora da Paraíba que servia. 
|Cilene Gomes |

Vi que elas conversavam bastante, eu queria entrar na conversa, mas não quis interromper. Mas acho que a senhora que servia percebeu, e olhava e sorria para mim o tempo todo, como se me convidasse a participar, mas fiquei constrangida com a reação da menina que senti estar meio aborrecida, pois parecia estar reclamando de algo ou se lamentando. Fiz algum comentário e a jovem senhora, ao ver meu interesse, começou a contar umas histórias de emprego que ela buscava em restaurantes uma ocasião e que ela teria sido aceita (por ter feito alguns pratos rapidamente), mas que não aceitou porque tinha que passar em baixo de um viaduto meio perigoso para chegar no trabalho. Disse também em meio à conversa com a moça que na padaria tinha sido contratada como copeira, mas que atuava na chapa, dando a entender que um "chapeiro" ganharia mais.

Quando fiz algum comentário (não lembro qual), percebi que a moça ao meu lado sorriu e que só então resolveu e também pediu um café. Ela disse que estava cansada e que queria se aposentar, dando risadas. Eu disse a ela, brincando, que também queria, mas que eu tinha bem mais idade que ela. Disse que tinha momentos que a gente ficava mesmo assim, desanimada com tudo, mas incentivei a menina e disse que logo ela se sentiria melhor. Desejei tudo de bom pra elas e fui embora. Ao sair, vi que a padaria chamava Vila Áurea dos Pães.

Chegando à galeria de arte naif, de novo me senti constrangida, pois embora os portões do sobrado estivessem abertos, para entrar na casa eu teria que chamar pela campainha e interfone. Uma moça me atendeu e eu perguntei o horário de funcionamento para ter certeza que eu estava dentro do horário. A moça disse que sim e que iria me abrir.

Veio então uma moça jovem, com cabelos escuros encaracolados e muito simpática, que me convidou a entrar. Disse a ela que gostaria de conhecer a galeria e também a casa. Ela disse que o interesse pela casa era normal. Falei que gostaria de começar de cima para baixo, e então subimos e eu observava os quadros pelas paredes, pensando que não poderia ficar o tempo necessário para apreciar aquela arte com tantos detalhes impressionantes. Conheci os cômodos de cima e num quarto dos fundos, onde funcionava um escritório, olhamos pela janela e a moça me disse que no casarão branco ao lado funcionava um Hostel.

Disse a ela que já conhecia a galeria pelo site e tinha feito downloads de várias pinturas de diferentes pintores, mas que havia notado que o site estava bem diferente. Disse que estava feliz de finalmente ter vindo conhecer a galeria, pela coincidência de fazer o curso ao lado.

A casa era linda e muito ampla, com um piso cerâmico margeado por vinhetas com motivo floral e um jardim muito agradável nos fundos, onde tinha um Gazebo e uma sala 
|Cilene Gomes |

parecendo estoque, com quadros enfileirados no chão e caixas de livros. Disse para a moça que queria comprar um livro anunciado no site, e daí tivemos que subir de novo para passar o cartão. Disse a ela que devia ser ótimo trabalhar naquele lugar. Ela disse que sim, que gostava muito e que era estagiária e estudava Artes Visuais na faculdade Belas Artes.

Havia uma senhora na sala, que conversando, descobri ser a dona da Galeria, junto ao seu marido que dá nome à galeria. Ela perguntou sobre o curso que eu estava fazendo no CEM e achou bem interessante. Disse a ela que era arquiteta e que, além da galeria, estava gostando muito de poder conhecer a casa. Disse também que estava fazendo uma observação etnográfica e que estava querendo pesquisar depois, de que época eram aqueles casarões do bairro. Ela disse que um dia tocou uma senhora que também estava curiosa por conhecer a casa, porque tinha morado lá quando criança. A casa era de 1925. Disse também para a dona, que a galeria me fazia lembrar uma loja de artesanato de Natal, chamada Alma Brasileira. Contei que o casal de donos desta loja viajava pelo Brasil afora em busca de artesanatos variados, típicos das distintas regiões do país. A galeria, com sua coleção de quadros de pintores brasileiros, me dava a mesma forte impressão de "alma brasileira". Disse que tinha que voltar para o curso e que voltaria outro dia para apreciar os quadros com mais calma.

\section{CONSIDERAÇÕES FINAIS - Paisagens, ambiência e urbanidade}

Indissociavelmente ligada às observações e aos diálogos, a paisagem estava lá e me tinha como centro onde quer que eu fosse. Participando da ambiência e arquitetura do espaço construído, a visão seriada do observador entrava em ação. As paisagens fragmentárias revelavam as camadas da história de Vila Mariana e as conexões físicas e simbólicas com a grande cidade metropolitana de São Paulo.

Da Estação Ana Rosa do Metrô, vias estruturantes e acessos locais descortinavam o lugar da habitação misturada aos comércios e serviços de tipologia variada, no porte, conteúdo e forma. Os sobrados eram geminados, ressaltavam em blocos e sua verticalidade era feita, às vezes, de três andares por causa da garagem no nível inferior. Alguns eram bem coloridos, e mais ainda quando "personalizavam" a atividade comercial ali praticada.

O horizonte também descerrava os casarões antigos e edifícios residenciais do bairro, em meio a ruas arborizadas, e algumas grandes edificações como o colégio Cristo Rei, a pirâmide com suas faces espelhadas em azul, o Instituto Biológico e as duas sedes da tradicional faculdade Belas Artes, transmigrada da Avenida Tiradentes para Vila Mariana. 
|Cilene Gomes |

O bairro continha em sua configuração resquícios e modernidades de época. Ruela de passagem faceava-se, de um lado, por imenso paredão com cerca elétrica de grande edifício e, de outro, por residências aparentemente mais antigas, simples ou descuidadas. Parede preta grafitada de loja, com rampa de skate salientando-se pela calçada, e pequena vila entranhada na quadra e fechada com portões à moda de condomínios. Prédios comportados e outros arranjos verticais poderosos em sua acumulação de capital.

Dentre as muitas lacunas de cenários não captados, alguns recortes a mais do olhar caminhante podem ser destacados: mar de carros e imensas laterais grafitadas da Avenida 23 de Maio (um verdadeiro realismo fantástico!); a escola de crianças Prime Garden, centro de meditação, clínica veterinária, padarias multifuncionais, mesas de bar ao ar livre.

O que mais dizer desse quadro imóvel latente de simbolismos? Paisagens e situações do todo observado levaram, pouco a pouco, a novas imersões no lugar apreendido em Vila Mariana, por meio das camadas de reflexão e significação sobre a urbanidade contemporânea.

Voltemos às duas cenas na calçada lateral do colégio Rosário. A função da comunicação, na primeira cena observada da fila de carros subindo rente à guia para a retirada dos alunos do colégio, mostrou-se criadora de uma ordem espacial urbana, no caso, do trânsito local da Rua Dr. Altino Arantes e, por isso, do tempo social cotidiano que deve fluir, evitando os congestionamentos físicos e mentais tão desgastantes. Sim, a urbanidade metropolitana insere-se no imaginário da velocidade (Santos, 2000) e, paradoxalmente, nos contrafluxos da livre circulação, das paradas nervosas, da ansiedade.

Saí contente com a interação e a observação da cena ao redor da pipoqueira. Sentiame plena, pois logo intui o potencial reflexivo da vivência. Percebi uma forma de sociabilidade criada no dia a dia, na saída do colégio. A rua, no espaço da calçada, era lugar de transição e parecia dotada de certa permeabilidade social. A pipoqueira, as crianças e seus responsáveis em seus automóveis, os guardas das portas do colégio e os passantes como eu, constituíram ali, naquele momento, uma instância da vida urbana agregada ao espaço escolar, onde as diferenças sociais estavam manifestas, mas não pareciam se conflitar. Se no início da observação o cotidiano me parecera ordinário, com cenas comuns, por meio dessa vivência, tornava-se agora, o espaço público comum a todos, onde uns cruzam e se encontram com outros o tempo todo e a urbanidade emerge do espaço vivido.

Pareceu-me que a ambiência da paisagem urbana deve brotar daí, das inúmeras situações similares extensivas à dimensão complexa da metrópole paulistana, certamente invisíveis ou inalcançáveis a muita gente. Lembrando Hillman (1993), parecia certo que somente a partir de uma vivência onde as pessoas prestam atenção na qualidade das coisas, 
|Cilene Gomes |

com pré-disposição às interações estabelecidas a partir de uma presença plena no lugar, é que talvez a urbanidade possa trazer mais alma ao lugar, equiparar-se à alma dos lugares.

Pensei que o sentido do lugar - no caso, o colégio, a rua, ou o bairro - pode ser construído e reconstruído coletivamente por meio dos diálogos entre as pessoas que cotidianamente os frequentam e/ou que apenas circundam aquele simples carrinho de pipoca, que ali se constituía como elemento de agregação e irradiação da vida social urbana.

Sem pretender esgotar a reflexão sobre o experimento, mas apenas situando outra linha em potencial para o persentir e a significação da urbanidade, é indispensável considerar junto às dinâmicas relacionais do lugar funcional de Vila Mariana a perspectiva simbólica para abordar o misto de encanto e desencanto, vivacidade e desolação compondo a ambiência social das paisagens.

Em última instância, pode-se conjecturar sobre as conexões e espaços por elas constelados, no ato da observação etnográfica e para além dele. A partir do primeiro relato e a caminho desse breve ensaio, as conexões tornaram-se lampejos exploratórios que levaram a leituras inesperadamente apropriadas (MAGNANI, 1996; URIARTE, 2012), e a insights de trabalho futuro ampliando a experiência e o estudo da etnografia urbana para aprofundar os sentidos da urbanidade metropolitana contemporânea.

Talvez pudessem ser um pouco mais trilhados, também, os caminhos da significação das conexões com lugares, tempos e vivências que vieram à tona na memória em distintos momentos da observação. Aliás, sobre as sincronicidades, outras conexões durante os dias do curso foram estabelecidas para além do âmbito restrito da experiência, a modo de coincidências significativas no âmbito da vida pessoal, o que desperta o interesse e leva a indagar: poderiam constituir a base de uma autoetnografia as conexões do experimento com as memórias, os instantes presentes e intuições de futuro do próprio observador? Camadas de reflexividade a partir de experiências interiores podem, por hipótese, conduzir a significações elucidativas a cerca de eventos exteriores, sociais, ou socioespaciais, portanto. Por exemplo, ao correlacionar a experiência pessoal de ser natural da cidade de São Paulo com a evolução urbana da cidade e de sua urbanidade.

No estudo da urbanidade contemporânea, o lugar metropolitano parece conter todas as medidas, mas, já dizia Goethe (HELLER, 1985), difícil é saber o que é diverso! O contentamento íntimo nascido com a realização do experimento veio da percepção de que viver plenamente o momento presente, sem as fronteiras que separam o trabalho do pesquisador da vivência do espaço público, do uso do tempo livre ou das relações intersubjetivas, talvez seja, na busca de desvelar um pouco mais a sociodiversidade, a essência do olhar etnográfico. 
|Cilene Gomes |

Jovchelovitch (1994) sugere que a sociedade e a história não podem ser estudadas como mera abstração, inseridas que estão na esfera do espaço público - onde a capacidade transformadora dos sujeitos sociais deve ser preservada como ação política e força de resistência a um mundo permeado pela violência concreta de relações sociais tão desiguais.

Tão perto e tão longe... uma transição se constela na modalidade do tempo kairós, o instante criador: o movimento afunilou-se encontrando na Vila Mariana, em São Paulo, o ponto indivisível, de máxima contração, onde tem lugar toda memória, vida e consciência, onde mora a utopia, de onde brotam imagens e expansões. Assim como o Aleph de Borges: o microcosmo onde se encontram todos os lugares da Terra e o próprio universo inconcebível, a dimensão de um formidável observatório, repleto, todavia, de entrelinhas.

\section{REFERÊNCIAS}

BORGES, J. L. O Aleph. São Paulo: Globo, 2001.

JOVCHELOVITCH, S. Vivendo a vida com os outros: intersubjetividade, espaço público e representações Sociais. In: JOVCHELOVITCH, S.; GUARESCHI, P. (Org.). Textos em Representações Sociais. Petrópolis: Vozes, 1994. p. 63-85.

HELLER, A. O cotidiano e a história. 2. ed. Rio de Janeiro: Paz e Terra, 1985.

HILLMAN, J. Cidade \& Alma. São Paulo: Studio Nobel, 1993.

MAGNANI, J. G. C. Quando o campo é a cidade: fazendo Antropologia na metrópole. In: MAGNANI, J. G. C.; TORRES, L. L. (Org.). Na metrópole - Textos de Antropologia Urbana. São Paulo, EDUSP, 1996, p. 1-30.

SANTOS, M. Por uma outra globalização. Rio de Janeiro: Record, 2000.

URIARTE, U. M. O que é fazer etnografia para os antropólogos. Ponto Urbe, v. 11, 2012. Disponível em: < http://journals.openedition.org/pontourbe/300 $>$. Acesso em $10 \mathrm{dez}$. 2020.

\section{Como citar este relato de experiência:}

\section{ABNT}

GOMES, C. A caminho do lugar e de passagem: tão perto e tão longe de Vila Mariana. InterEspaço: Revista de Geografia e Interdisciplinaridade, v. 6, e202031, 2020. Disponível em: <http://dx.doi.org/10.18764/2446-6549.e202031>. Acesso em: 25 jan. 2020.

APA: 
|Cilene Gomes |

Gomes, C. (2020). A caminho do lugar e de passagem: tão perto e tão longe de Vila Mariana. InterEspaço: Revista de Geografia e Interdisciplinaridade, v. 6, e202031. Recuperado em 25 janeiro, 2020, de http://dx.doi.org/10.18764/2446-6549.e202031

\section{@ccreative}

This is an open access article under the CC BY Creative Commons 4.0 license.

Copyright (C) 2020, Universidade Federal do Maranhão.

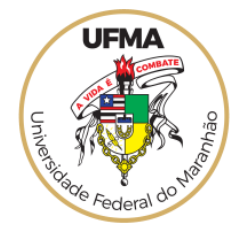

